\title{
SELEÇÃO DE ROTAS DE FUGA PARA EVACUAÇÃO DE UMA REFINARIA DE PETRÓLEO UTILIZANDO FERRAMENTAS DE ANÁLISE DE DISPERSÃO DE SUBSTÂNCIAS QUÍMICAS E SISTEMAS DE INFORMAÇÕES GEOGRÁFICAS ${ }^{1}$
}

\author{
Guilherme de Oliveira Ferreira ${ }^{a}$, Virgílio José Martins Ferreira Filho ${ }^{a}$ \\ ${ }^{a}$ Instituto Professor Alberto Luiz de Coimbra de Pós-graduação e Pesquisa em Engenharia (COPPE), \\ Programa de Engenharia de Produção \\ Universidade Federal do Rio de Janeiro, Rio de Janeiro - RJ, Brasil
}

Recebido 19/01/2018, aceito 01/08/2019

\begin{abstract}
RESUMO
Para elaboração de um plano de evacuação em uma empresa petroquímica, devido a vazamento de substâncias tóxicas, é necessário que os gestores conheçam o número de pessoas presentes na planta, a geografia do local e também a forma como diferentes substâncias químicas se comportam quando dispersas pelo ar e qual a extensão da área afetada pelo vazamento. $\mathrm{O}$ presente trabalho tem como objetivo a elaboração de um modelo matemático para determinação de rotas de fuga para colaboradores de uma planta petroquímica, considerando a área afetada pelo vazamento de produtos químicos, utilizando ferramentas de análise de dispersão de substâncias químicas e Sistemas de Informação Geográficos. É construído um modelo de roteamento em dois estágios utilizando a formulação de fluxo em grafos que permite rastreamento das rotas individuais de pessoas e dos veículos utilizados para evacuação. Sua aplicabilidade é demonstrada através de estudos de caso de evacuação em uma refinaria de petróleo.
\end{abstract}

Palavras-chave: Planos de evacuação industrial, Logística humanitária, Roteamento de veículos em emergências, Modelo de localização-roteamento.

\begin{abstract}
To draw up an evacuation plan in a chemical plant, due to leakage of chemicals, it is necessary for managers to know the number of people in site, the geography of the place and how different chemicals behave when dispersed in the air and the extent of the affected area by the leak. This paper aims at developing a mathematical model to determine escape routes for employees of a chemical plant considering the area affected by the spill of chemicals, using modeling and dispersion analysis tools for chemicals and their related risks. The model is built as a two-stage routing model using the flow formulation for graphs. The model allows tracking of individual routes of people in a particular production unit and the vehicles used for evacuation. Lastly, the applicability of the model is demonstrated through a case study of evacuation in an oil refinery.
\end{abstract}

Keywords: Industrial evacuation plan, Humanitarian logistics, Emergency vehicle routing, Location-routing model.

*Autor para correspondência. E-mail: guilherme.ferreira@ufrj.br

DOI: 10.4322/PODes.2019.005

${ }^{1}$ Todos os autores assumem a responsabilidade pelo conteúdo do artigo. 


\section{Introdução}

Instalações de alto risco, como plantas petroquímicas, estações de tratamento de esgoto e plantas de geração de energia, são extremamente necessárias para sustentação e desenvolvimento de todos os países, fornecendo a energia necessária para suas indústrias, agricultura, sistemas de transporte, etc.

Porém, o aumento considerável da produção e do consumo de energia global, principalmente após a Segunda Guerra Mundial, faz com que tais instalações passem a armazenar grandes quantidades de energia e substâncias perigosas em um único lugar. Além disso, pressões econômicas fazem com que as plantas industriais aumentem não apenas em tamanho, mas também em complexidade, fazendo com que até mesmo substâncias aparentemente inofensivas tornem-se um risco quando armazenadas em grande quantidade. Por estes motivos, tais instalações apresentam um potencial para ocorrência de acidentes que não pode ser ignorado. Acidentes estes que podem resultar em morte ou ferimento de um grande número de pessoas, dentro e fora das plantas industriais, ou causar considerável dano a instalações e/ou ao meio ambiente. (ILO, 1988).

Grandes desastres industriais estão presentes desde o surgimento das indústrias, com a revolução industrial, como a explosão de um armazém em uma planta de produção de fertilizantes, ocorrido em Oppau, Alemanha (1921), que vitimou 561 pessoas. Porém, foram os acidentes significativos da segunda metade do século passado, tais como Seveso (1976), Three Mile Island (1979), Bhopal (1984), Chernobyl (1986) e Piper Alpha (1988), que alertaram as autoridades e indústrias da necessidade de controlar, gerenciar e minimizar os riscos em seus processos industriais.

Porém nenhuma planta industrial pode ser projetada de forma absolutamente segura, de modo que mesmo com todas as medidas preventivas e normas de segurança implantadas, um evento inesperado pode ocorrer e desencadear um desastre, como vazamentos de gases tóxicos, incêndios e/ou explosões.

Por isso, as organizações necessitam estar preparadas para responder apropriadamente a possíveis acidentes. A preparação para desastres envolve atividades que têm como foco a seleção de ações a serem tomadas antes que um desastre ocorra de modo a otimizar a aplicação de recursos materiais, financeiros e humanos durante a resposta a um desastre. Tais atividades incluem alocação de recursos, planejamento de transporte e evacuação de colaboradores, treinamento de equipes de resgate e localização de abrigos e sistemas de alerta.

O presente estudo tem como objetivo apresentar um conjunto de modelos matemáticos para determinação de rotas de fuga para veículos e pedestres em uma refinaria de petróleo de grande porte, em um eventual vazamento de produtos químicos, utilizando-se de Sistemas de Informação Geográficos para determinar as áreas afetadas pelo vazamento. Os modelos apresentam como saída o número e localização de Pontos de Reunião necessários para agrupar os pedestres sendo evacuados, o número de veículos necessários para evacuação e a localização dos estacionamentos para abrigar os veículos utilizados durante a evacuação. Além disso, os modelos permitem rastreamento de rotas individuais de pessoas e veículos dentro da rede de vias da refinaria sem a necessidade de aplicar um algoritmo pós-otimização.

$\mathrm{Na}$ sequência, a segunda seção apresenta o conceito de evacuação de área e os atuais estudos elaborados na área. A terceira seção traz a definição do problema abordado e a modelagem proposta para solução do problema. Na quarta seção são apresentados os dados utilizados para a experimentação dos modelos. Na quinta seção são expostos de forma sucinta os resultados obtidos. Por fim, a sexta e última seção é dedicada à conclusão e considerações finais a respeito do estudo desenvolvido. 


\section{Evacuação de Área}

Evacuação de área é definida como um processo onde pessoas ameaçadas por um evento são movidas de locais expostos a tal evento para locais seguros, de modo a reduzir a vulnerabilidade à saúde e vida de cada pessoa (Saadatseresht et al., 2009). Evacuações de área são fundamentais para a proteção de uma população em eventos como incêndios, furacões, tsunamis, desastres industriais, atentados terroristas, etc. que podem atingir uma determinada localidade (Brachman e Dragicevic, 2014).

$\mathrm{O}$ rompimento de uma barragem de rejeitos de uma mineradora em Brumadinho (MG), em janeiro de 2019, que vitimou cerca de 310 pessoas, entre mortos e desaparecidos; o tremor de 7,1 graus que atingiu o México em setembro de 2017, vitimando 293 pessoas; os furacões Irma e Maria, que atingiram o Caribe e os Estados Unidos em setembro de 2017, deixando mais de 150 mortos e obrigaram a evacuação de mais de 70.000 pessoas em Porto Rico; o atentado a bombas na Somália, outubro de 2017, que vitimou mais de 300 pessoas; e o rompimento de duas barragens de rejeitos de uma mineradora em Mariana (MG), novembro de 2015, que vitimou 13 pessoas e obrigou a completa evacuação do distrito de Bento Rodriguez, além de outras dezenas de eventos que ocorrem anualmente ao redor do mundo, são lembretes constantes da necessidade de planejamento para evacuação de áreas em resposta a desastres naturais e antropogênicos. De fato, Marinho et al. (2018) aponta que apenas no ano de 2017 foram registrados 529 desastres, sendo 361 desastres naturais e 168 desastres antropogênicos.

Embora grandes problemas de evacuação de área se tornaram evidentes durante a Segunda Guerra Mundial, o primeiro grande estudo sobre evacuação em larga escala foi realizado em 1961, em resposta ao furacão Carla, que atingiu a costa do Texas, Estados Unidos, e obrigou a evacuação de aproximadamente 250 mil pessoas (Johnson Jr e Zeigler, 1986). Porém, o interesse em estudos de evacuação envolvendo desastres antropogênicos aflorou apenas após os desastres de Seveso, Itália (1976) e Three Mile Island, Estados Unidos (1979) (Cova e Church, 1997).

Evacuação de área é considerada a atividade mais importante em resposta a desastres. Por isso, elaboração e treinamento apropriado de um plano de evacuação são partes primordiais da etapa de preparação para um desastre (Yi e Özdamar, 2007; Saadatseresht et al., 2009).

Para que modelos de evacuação sejam precisos é necessário que gestores saibam previamente a distribuição espacial das pessoas a serem evacuadas, dos riscos no local, a localização de áreas seguras e quais as rotas e modais de transporte disponíveis (Cova e Johnson, 2003).

Uma vez que a ordem de evacuação de uma área é dada, o principal objetivo é retirar todos os habitantes da área, no menor tempo possível, e com o mínimo de fatalidades, ferimentos e danos à propriedade. Diversos modelos matemáticos e ferramentas foram desenvolvidos nos últimos anos com este objetivo.

Embora existam muitos estudos relacionados à evacuação de área, eles possuem diferentes perspectivas, tais como: aperfeiçoar estratégias de controle de tráfego durante desastres (Cova e Church, 1997; Cova e Johnson, 2003), maximização de fluxo na rede de transporte (Kalafatas e Peeta, 2009; Brachman e Dragicevic, 2014), comportamento dos evacuados frente aos riscos existentes (Pidd et al., 1996; Liu et al., 2006) e seleção de abrigos e seleção de rotas de fuga (Yamada, 1996; Yi e Özdamar, 2007; Alçada-Almeida et al., 2009; Campos et al., 2012), dentre outros.

Este estudo se baseia na abordagem de Brachman e Dragicevic (2014) para identificação de áreas afetadas por vazamentos de gases tóxicos de plantas industriais. Em seu estudo, os autores se utilizam de ferramentas para análise de produtos químicos e sistemas de informações geográficos que permitem identificar, previamente, as áreas afetadas por um vazamento químico, de acordo com as características geográficas do local do acidente e das características físicas da substância em estudo. Porém, enquanto Brachman e Dragicevic buscam identificar o comportamento dos evacuados frente a uma situação de risco, de modo a prever gargalos e congestionamentos no sistema de transporte urbano no entorno da planta industrial, o presente estudo visa selecionar os abrigos e as rotas de fuga mais seguras para colaboradores durante a 
evacuação de uma área de risco, no ambiente industrial. Até o presente momento, os autores deste trabalho não têm conhecimento de estudos envolvendo a seleção de rotas de fuga, para elaboração de Planos de Evacuação de Área em ambientes industriais, utilizando Sistemas de Informações Geográficas e ferramentas de análise de dispersão de produtos químicos.

\section{Seleção das Rotas de Fuga da Refinaria}

O presente estudo tem como objetivo apresentar um conjunto de modelos matemáticos para seleção de rotas de fuga, para os colaboradores e veículos dentro de uma refinaria de petróleo, auxiliando a elaboração de um Plano de Evacuação de Área (PEA) para situações de emergência.

Um PEA contempla ações específicas a serem desenvolvidas para garantir que todas as pessoas presentes na refinaria sejam conduzidas para locais pré-definidos, identificados e considerados seguros para a concentração do pessoal evacuado.

Existem sempre dois estágios na evacuação de uma refinaria. No primeiro estágio as pessoas são reunidas em um ponto seguro e próximo à unidade produtiva à qual estão designadas, chamado Ponto de Reunião (PR). No segundo estágio as pessoas são deslocadas, através de veículos, para fora da refinaria. Desta forma, os modelos matemáticos também são divididos em dois estágios. No primeiro estágio o objetivo é encontrar as rotas que cada colaborador deve percorrer, a partir de sua unidade, até um dos PR pré-determinados. No segundo, o objetivo é encontrar as rotas que cada um dos veículos deve percorrer, a partir de um dos estacionamentos, para recolher as pessoas de um dos PR e se dirigir a uma das saídas da refinaria, de forma segura e o mais rapidamente possível.

Neste ponto, é importante notar que os modelos propostos não consideram as áreas necessárias para manobra dos veículos em cada Ponto de Reunião. Além disso, não são considerados os tempos necessários para embarque dos evacuados nos veículos ou o tempo de espera de cada veículo para início do embarque dos passageiros devido à ocupação das áreas (ou plataformas) de embarque. Tais hipóteses simplificadoras foram adotadas para facilitar a implantação dos modelos, visto que o tempo de embarque dos evacuados nos veículos, assim como toda a operação dos veículos em situações de emergência, é fortemente dependente de uma preparação adequada para resposta a desastres, incluindo treinamento dos evacuados e das equipes de resgate, podendo haver uma grande variação em seu tempo de operação.

A abordagem seguida neste trabalho, de modelar o problema em dois estágios, seguiu os procedimentos adotados na realidade pela refinaria em estudo. Uma abordagem alternativa consiste em modelar o problema integrando os dois estágios e resulta em um modelo muito mais complexo. Testes preliminares conduzidos nesta linha levaram a tempos de execução consideravelmente altos, sem melhoria dos resultados. O desenvolvimento desta linha é deixado como sugestão de trabalho futuro.

\subsection{Identificação das Áreas Afetadas pelo Vazamento}

Para modelar a evacuação de uma área afetada por vazamento de um produto químico/tóxico é necessário saber a extensão da área afetada pela dispersão do produto. Para isto foram utilizados os softwares ALOHA (Areal Locations Of Hazardous Atmospheres) e MARPLOT (Mapping Application for Response, Planning and Local Operational Tasks), desenvolvidos pela Agência de Proteção Ambiental dos Estados Unidos. A utilização destas ferramentas é baseada na abordagem proposta por Brachman e Dragicevic (2014), citada anteriormente.

O ALOHA é uma ferramenta para modelagem de dispersão atmosférica utilizada para analisar dispersão de nuvens tóxicas oriundas de vazamentos de produtos químicos. A ferramenta permite estimar a dispersão de uma nuvem tóxica, baseando-se nas características tóxico-físicas do material estudado, condições atmosféricas e geografia do local. O ALOHA é capaz de indicar as áreas afetadas por um vazamento de um produto químico, chamadas zonas 
de risco, para diversas formas de incidentes como dispersão de nuvens de gás tóxico, incêndios e explosões. Estas zonas de risco podem ser mostradas em diferentes mapas através de Sistemas de Informações Geográficas (SIG), como o MARPLOT, permitindo uma visualização precisa das áreas afetadas.

A ferramenta MARPLOT é um SIG que possui diversas opções de mapas, tais como imagens por satélite, ruas e avenidas, etc. comumente utilizados para gerenciamento baseado em posicionamento geográfico. SIG possuem capacidade de modelar e apresentar diferentes cenários para previsão e estimativas de impacto de desastres.

\subsection{Estágio 1 - Roteamento de Colaboradores aos Pontos de Reunião}

O modelo segue uma formulação de fluxo em grafos, cuja função objetivo é minimizar a maior distância que os colaboradores precisam percorrer até chegar a um dos PR, de modo que as distâncias percorridas por todos colaboradores sejam semelhantes.

O mapa da refinaria é transformado em um grafo onde cada arco representa uma via distinta da refinaria e cada vértice representa uma intercessão de vias. De modo que um arco (m, n) representa a via que une as intercessões de vias m e n. A Figura 1 apresenta o grafo elaborado a partir da configuração de vias da refinaria.

Figura 1: Grafo representativo das vias da refinaria em estudo.

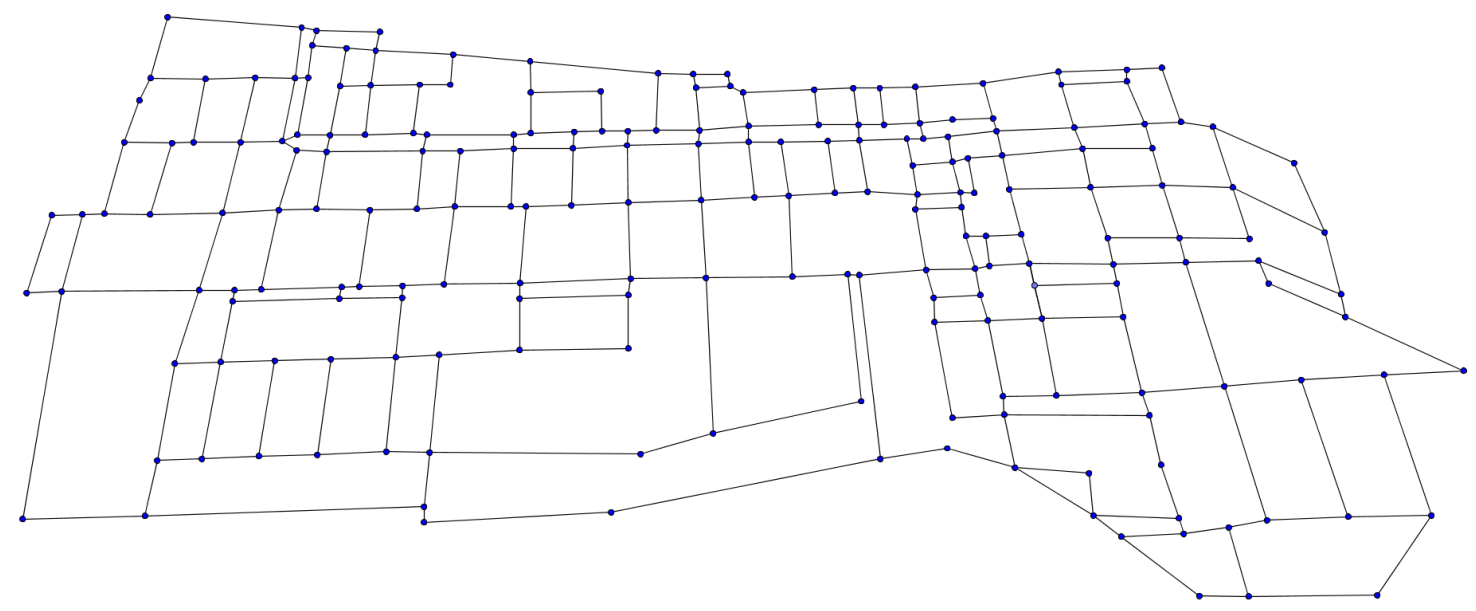

Fonte: Elaborada pelos autores.

Para completar o grafo são criados dois vértices fictícios, uma origem (de onde partem todos os trabalhadores) e um sumidouro (para onde os trabalhadores se dirigem). Além disso, são criados vértices fictícios adjacentes ao vértice origem do grafo, representando as unidades da refinaria. Os funcionários de uma unidade u obrigatoriamente ativam o arco (origem, u). Os demais arcos adjacentes a u são as vias que dão acesso à unidade. Da mesma forma, são criados novos vértices fictícios representando os $\mathrm{PR}$, que são adjacentes ao vértice sumidouro, o arco (PR, sumidouro) é ativado por uma unidade u caso o PR seja o destino dos evacuados da unidade u. A Figura 2 apresenta um esquema da inclusão dos vértices de origem, sumidouro, unidades e PR no grafo. 
Figura 2: Inserção dos vértices fictícios representando as unidades e PR no grafo gerado.

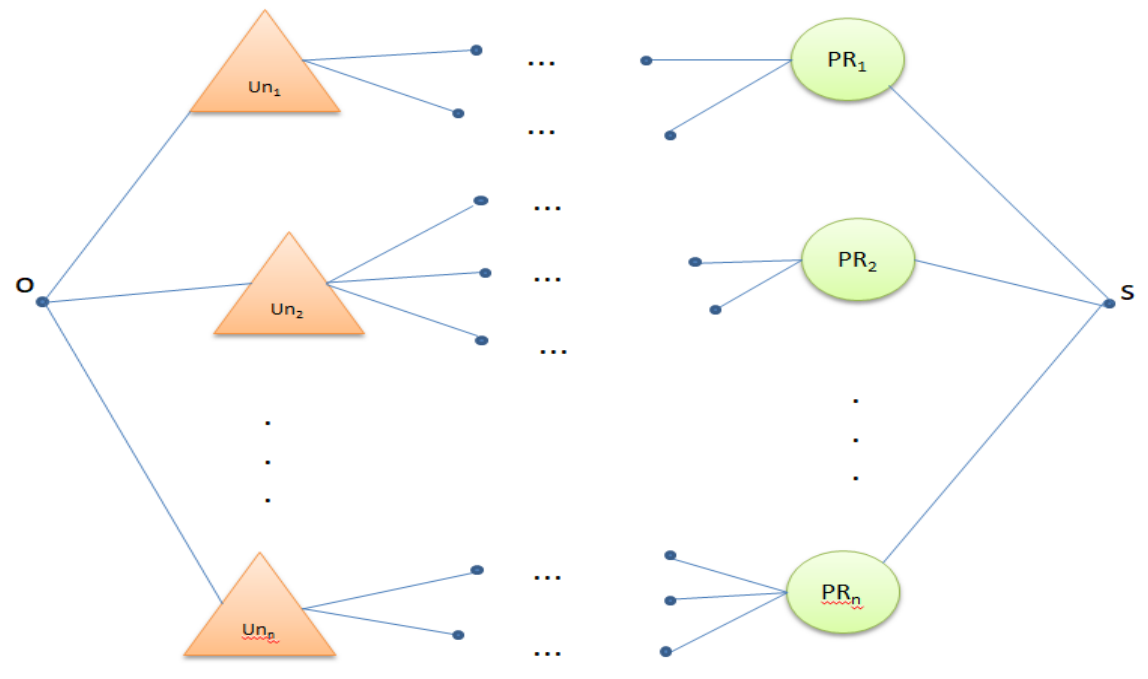

Fonte: Elaborada pelos autores.

As premissas adotadas para elaboração deste modelo são apresentadas no Quadro 1.

Quadro 1: Premissas do modelo de reunião dos colaboradores.

i. $\quad$ Todas as pessoas presentes em uma unidade devem se dirigir a um mesmo PR.

ii. As vias para pedestres na refinaria são suficientes para o escoamento do fluxo de colaboradores sem atrapalhar o trânsito de veículos, por isso sua capacidade de fluxo é considerada $+\infty$, neste estágio.

iii. Se um PR estiver sob uma das zonas de riscos, identificadas pelo ALOHA, ele não deve receber evacuados, de modo a não expô-los a riscos desnecessários. Da mesma forma, vias contidas em zonas de risco não são utilizadas para evacuação.

iv. Se uma unidade estiver dentro de uma das zonas de risco, suas vias de acesso estão contidas em uma das zonas de risco identificadas, porém podem ser utilizadas para evacuar a unidade.

Sejam as seguintes variáveis de decisão e parâmetros:

Variáveis de Decisão:

$Y_{m n u}=$ Indica se as pessoas de uma unidade u passam pelo arco $(m, n)($ binária $)$, $R=$ Indica o tamanho da maior rota que um colaborador deve percorrer.

Parâmetros:

$$
\begin{gathered}
P=\text { fluxo total }=\text { número total de unidades, } \\
A_{m}=\text { conjunto de vértices adjacentes a um vértice } m, \\
L=\text { conjunto das zonas de risco existentes, } \\
V=\text { conjunto de vértices, } \\
U=\text { conjunto de unidades, } \\
P R=\text { conjunto de Pontos de Reunião, } \\
o=\text { vértice origem, } \\
s=\text { vértice sumidouro, }
\end{gathered}
$$




$$
\begin{gathered}
d_{m n}=\text { distância entre os vértices } m \text { e } n, \\
N_{u}=\text { número de pessoas na unidade } u, \\
C_{p r_{j}}=\text { capacidade do ponto de reunião } j, \\
c_{m n}=\text { capacidade de fluxo de pessoas no trecho }(m, n), \\
C_{m n}=\text { capacidade de fluxo de veículos no trecho }(m, n), \\
C O=\text { capacidade dos veículos utilizados para evacuação, } \\
\lambda_{l m} \in\{0,1\}, \text { onde } \lambda_{l m}=\left\{\begin{array}{c}
0 \text { se o vértice } m \in \text { zona de risco } l, \\
1 \text { caso contrário. }
\end{array}\right.
\end{gathered}
$$

O problema relativo ao estágio 1 objetiva minimizar a maior distância percorrida pelos colaboradores de uma unidade $u$ até chegar a um PR, e pode ser formulado da seguinte forma:

Modelo Estágio 1

Sujeito a:

\section{$\operatorname{Min} R$}

$$
\begin{aligned}
& R \geq \sum_{m \in V, n \in A_{m}} Y_{m n u} * d_{m n}, \quad \forall u \in U \\
& \sum_{n \in A_{m}} Y_{m n u}-\sum_{n \in A_{m}} Y_{n m u}=0, \quad \forall m \in V, u \in U \\
& \sum_{u \in U, m \in A_{j}} Y_{m j u} * N_{u} \leq C_{p r_{j}} * \lambda_{l j}, \quad \forall j \in P R, \forall l \in L, \forall j \in P R \\
& \sum_{p \in U} Y_{o p u}=1, \quad \forall u \in U \\
& \begin{array}{l}
\sum_{u \in U} Y_{m n u} * N_{u} \leq c_{m n} * \lambda_{l m}, \quad \forall m \in V, n \in A_{m}, \forall l \in L \\
\sum_{u \in U} Y_{m j u} * N_{u} \leq C O * C_{m j} *\left|A_{j}\right|, \quad \forall j \in P R, \forall m \in A_{j}
\end{array} \\
& Y_{\text {sou }}=1, \quad \forall u \in V \\
& Y_{\text {ouu }}=1, \quad \forall u \in U \\
& Y_{m n u} \in\{0,1\}, \quad \forall m, n \in V, u \in U \\
& R \geq 0
\end{aligned}
$$

A função objetivo de minimização do tempo máximo (1) tem como objetivo equilibrar os tempos de evacuação, de modo a garantir que o tempo de evacuação do colaborador que demora mais para chegar ao ponto de reunião seja o menor possível. As restrições (2) completam a função objetivo, tornando o problema um problema de minimizar a maior distância $R$. As restrições (3) são de equilíbrio de fluxo em grafos. As restrições (4) garantem que o número de pessoas que chega a um PR é menor ou igual à capacidade do PR. O fator $\lambda_{l j}$ indica se o PR $j$ se encontra sobre uma zona de risco $l$. As restrições (5) garantem que todas as unidades são evacuadas. As restrições (6) garantem que o número de pessoas transitando por um arco é menor do que a capacidade do arco. $\mathrm{O}$ fator $\lambda_{l m}$ indica se o trecho (arco) $m$ pode encontra-se sobre uma zona de risco $l$. As restrições (7) garantem que o número de pessoas direcionadas a um PR é menor do que a capacidade dos veículos de extrair estas pessoas do PR, de modo que, durante o segundo estágio da evacuação (representado pelos modelos da Seção 3.3), não 
existam mais pessoas em um PR do que os veículos tenham capacidade para evacuar. As restrições (8) garantem que todos os colaboradores (representados por sua unidade) chegam a um PR, passando pelo vértice sumidouro. As restrições (9) garantem que os colaboradores de cada unidade transitam pelo arco inicial que representa a respectiva unidade. As restrições (10) e (11) indicam a natureza das variáveis.

O primeiro estágio do modelo permite identificar o número de pessoas alocadas em cada um dos PR. Além disso, indica para quais PR os colaboradores de uma unidade produtiva devem se dirigir e qual a rota ótima que cada colaborador deve seguir para chegar ao seu destino.

Uma vez que todos os colaboradores se encontram nos respectivos PR, veículos são responsáveis por buscá-los e retirá-los em segurança da refinaria. Os resultados do primeiro estágio são utilizados como entrada de dados para o segundo. Esta operação é descrita a seguir.

\subsection{Estágio 2 - Roteamento dos Veículos para Retirada dos Colaboradores}

O segundo estágio da evacuação é dividido em duas partes e cada parte é representada por um modelo matemático distinto. Em um primeiro momento, são encontradas as rotas ótimas para que cada veículo saia de um estacionamento e chegue a um dos PR para extração dos evacuados. Em um segundo momento, são encontradas as rotas ótimas para que os veículos evacuem a refinaria, partindo de um dos PR em direção a uma das saídas da refinaria.

Os modelos para roteamento de veículos também seguem a formulação de fluxo em grafos, cujo objetivo é minimizar o tempo total necessário para todos os veículos evacuarem a refinaria, representada pelo grafo mostrado na Figura 1. Vértices fictícios de origem e sumidouro também são adicionados ao grafo que representa as vias da refinaria, em ambos os momentos. No primeiro momento é criado um conjunto de vértices $\mathrm{E}$ que representa os estacionamentos da refinaria e são adjacentes ao vértice de origem do grafo, e um conjunto de vértices PR que representa os Pontos de Reunião da refinaria, e são adjacentes ao vértice sumidouro. As vias de acesso aos estacionamentos são adjacentes aos vértices pertencentes a $\mathrm{E}$, e as vias de acesso aos PR são adjacentes aos vértices pertencentes a PR. A Figura 3 apresenta um esquema da inclusão destes vértices no grafo da refinaria. Da mesma forma, no segundo momento são criados conjuntos PR e S, que representam os Pontos de Reunião e as saídas da refinaria, respectivamente, adjacentes aos vértices de origem e sumidouro, respectivamente. A Figura 4 apresenta um esquema da inclusão dos vértices de PR e saídas da refinaria no segundo modelo.

Figura 3: Inserção dos vértices fictícios de estacionamento e PR no primeiro modelo do segundo estágio.

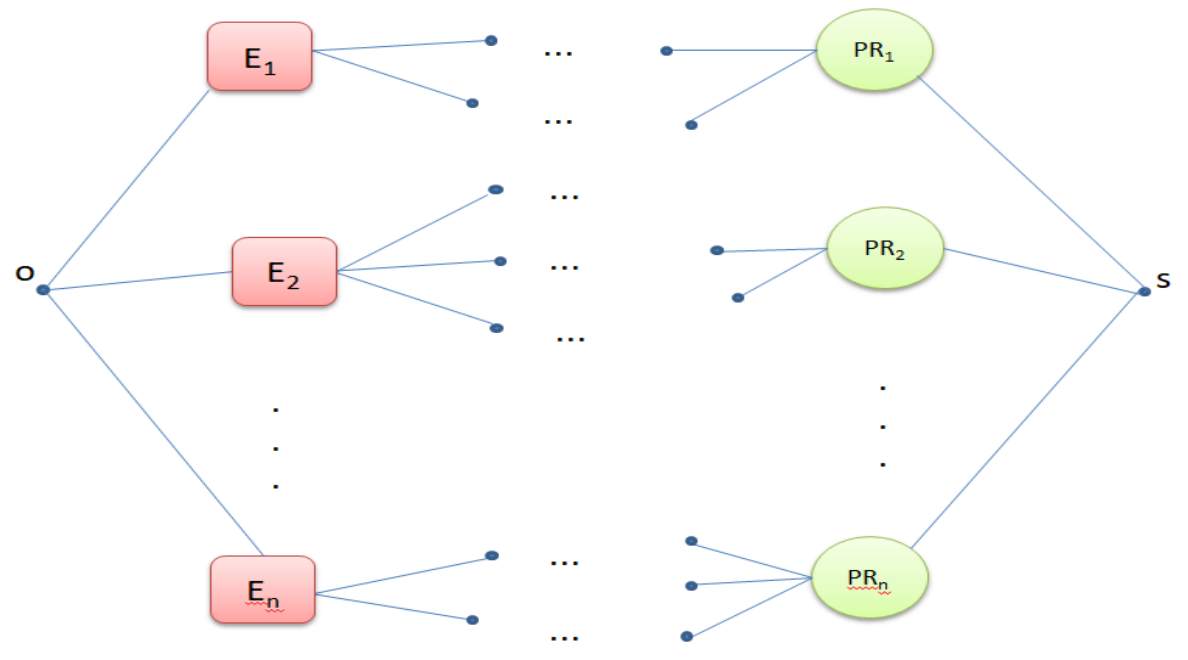

Fonte: Elaborada pelos autores. 
Figura 4: Inserção dos vértices fictícios de PR e saídas no segundo modelo do segundo estágio.

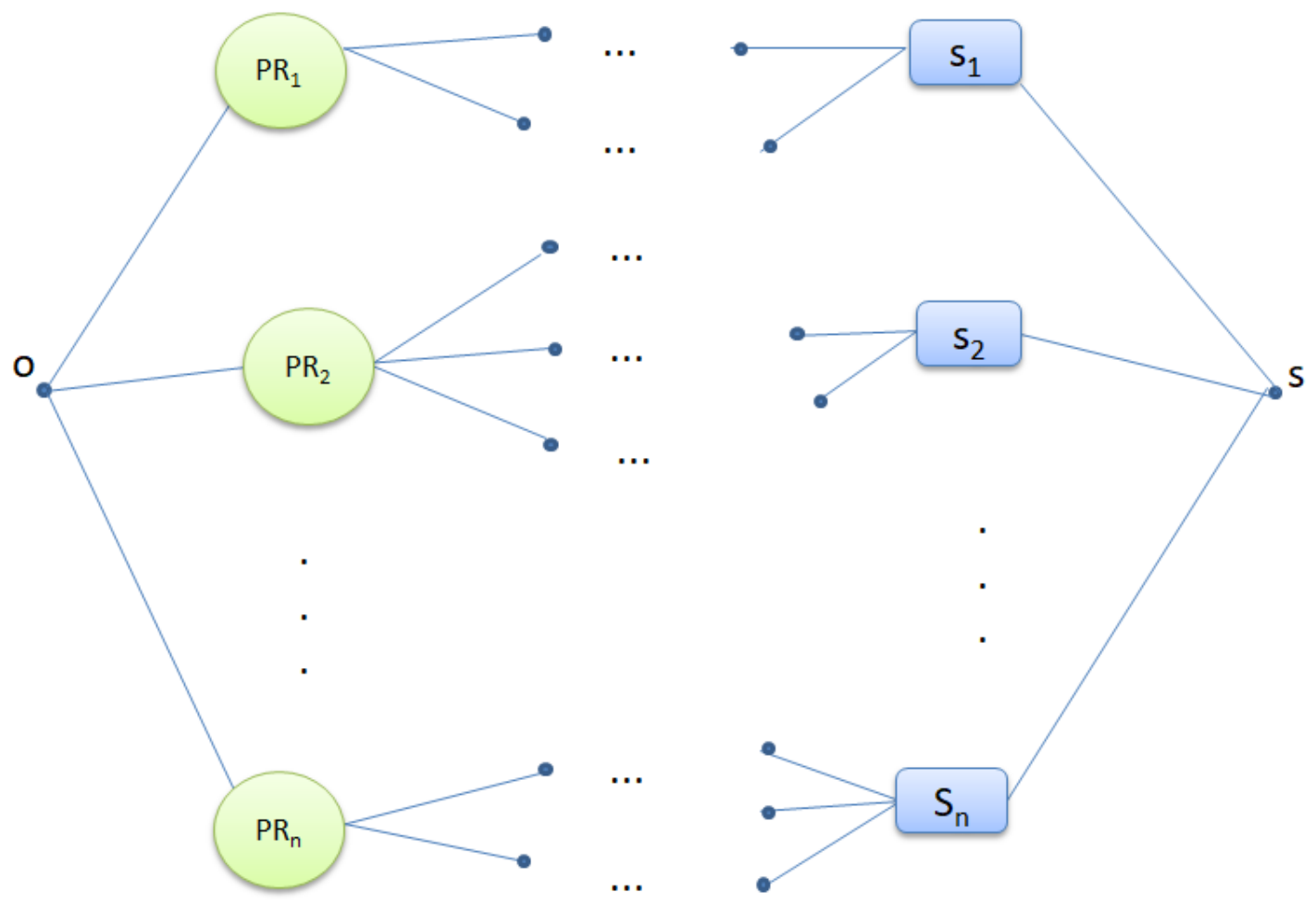

Fonte: Elaborada pelos autores.

O Quadro 2 apresenta as premissas adotadas para elaboração deste modelo.

Quadro 2: Premissas do modelo de evacuação dos veículos.

i. Cada um dos veículos utilizados deve passar por apenas um dos PR antes de evacuar a refinaria, de modo a deixar a refinaria o mais rápido possível e não expor os colaboradores a riscos desnecessários, uma vez que os veículos responsáveis pela evacuação se deslocam imediatamente para fora da refinaria após recolher os colaboradores, e não precisam trafegar por vias da refinaria transportando evacuados. Isto também auxilia a diminuir o trafego de veículos nas vias da refinaria, que possuem capacidade de trafego limitada para veículos.

ii. Embora a frota seja homogênea e os veículos possuam velocidade máxima de condução igual, as velocidades máximas de segurança permitidas por cada uma das vias é diferente. Por isso o objetivo não é diminuir a distância e sim o tempo necessário para evacuação dos veículos.

iii. O tempo necessário para um veículo atravessar uma área (conjunto de vértices e arestas) que se encontra sob uma zona de risco deve ser menor que o tempo máximo de exposição permitido (fornecido pelo ALOHA e por organizações reguladoras e de saúde) para a substância em estudo.

A seguir, são apresentados os modelos desenvolvidos para o segundo estágio do problema. Além disso, são apresentadas e explicadas as variáveis de decisão e parâmetros específicos utilizados para o segundo estágio do problema. É importante observar que os parâmetros apresentados no primeiro estágio do problema se mantêm os mesmos no segundo estágio e por isso não são listados a seguir. 
Variáveis de decisão:

$$
\begin{gathered}
X_{m n k}=\text { Indica se o veículo } k \text { passa pelo arco entre } m \text { e } n \text { (binária) } \\
T_{m k}=\text { Instante em que veículo } k \text { chega ao vértice } m
\end{gathered}
$$

Parâmetros:

$$
\begin{gathered}
L=\text { conjunto de zonas de risco existentes } \\
K=\text { conjunto de veículos existentes } \\
E=\text { conjunto de estacionamentos } \\
o=\text { vértice origem } \\
s=\text { vértice sumidouro }
\end{gathered}
$$

$\delta_{l}=$ tempo de exposição máximo permitido para a zona de risco $l$

$$
\text { CO = capacidade dos veículos }
$$

$$
F=\text { fluxo total }=\text { número total de veículos }
$$$$
M=\text { número suficientemente grande }
$$$$
d_{m n}=\text { distância do vertice } m \text { ao } n
$$

Vel $l_{m n}=$ velocidade de segurança permitida no trecho $(m, n)$

$$
T e_{m n}=\frac{d_{m n}}{V e l_{m n}}=\text { tempo de um ônibus ir do vertice } m \text { ao } n
$$

$N P_{p}=$ número de pessoas em cada ponto de reunião $p \in P R$

$N O_{p}=$ número de ônibus que passa por cada ponto de reunião $p \in P R$

$C E_{j}=$ capacidade do estacionamento $j$, dada em número de veículos

$C_{m n}=$ capacidade de fluxo do trecho $(m, n)$, dada em número de veículos

\subsubsection{Modelo para Seleção de Rotas dos Veículos a partir dos Estacionamentos}

Função Objetivo: Minimizar a soma dos tempos necessários para os veículos acessarem os PR.

Sujeito a

$$
\operatorname{Min} \sum_{m \in V,} X_{m \in A_{m},} * T e_{m n}
$$

$$
\begin{gathered}
\sum_{n \in A_{m}} X_{m n k}-\sum_{n \in A_{m}} X_{n m k}=0, \quad \forall m \in V, k \in K \\
\sum_{k \in K} X_{s o k} \leq F \\
\sum_{k \in K} X_{o j k} \leq C E_{j}, \quad \forall j \in E \\
\sum_{p \in P R} X_{p s k} \leq 1, \quad \forall k \in K \\
\sum_{k \in K} X_{p s k} * C O \geq N P_{p}, \quad \forall p \in P R \\
\sum_{k \in K} X_{m n k} \leq C_{m n}, \quad \forall m \in V, n \in A_{m}
\end{gathered}
$$




$$
\begin{gathered}
T_{n k} \geq T_{m k}+T e_{m n}-M *\left(1-X_{m n k}\right), \quad \forall m, n \in V, k \in K \\
T_{n k}-T_{m k} \leq \delta_{l}, \quad \forall k \in K, l \in L, m \in L, n \in L \\
X_{m n k} \in\{0,1\}, \quad \forall m, n \in V, k \in K
\end{gathered}
$$

Diferentemente da função objetivo (1), a função objetivo (12) visa minimizar a soma dos tempos necessários para todos os veículos evacuarem a refinaria e minimizar o maior tempo de evacuação. Esta função é utilizada por que os veículos precisam sair o mais rapidamente possível da refinaria, minimizando os riscos para os colaboradores. Por isso minimizar o tempo total para evacuação é uma escolha mais coerente como função objetivo para o segundo estágio do modelo, mesmo que isso implique que um veículo acabe levando mais tempo para percorrer as vias da refinaria em direção a uma das saídas. A restrição (13) é a restrição de equilíbrio de fluxo em grafos. A restrição (14) assegura que o fluxo total de veículos que evacua a refinaria é menor ou igual ao número total de veículos. A restrição (15) garante que o número de veículos que parte de um estacionamento é menor do que a capacidade do estacionamento. A restrição (16) assegura que cada um dos veículos utilizados para evacuação passe por no máximo um $P R$, ou seja, se um veículo for utilizado para evacuação, ele deve evacuar apenas um PR antes de se dirigir a uma das saídas da refinaria. A restrição (17) garante que o número de veículos que passa por cada um dos PR é suficiente para retirar todos os evacuados presentes, uma vez que um único veículo dificilmente será capaz de retirar todos os colaboradores de um único PR. A restrição (18) é a restrição de capacidade dos arcos. A restrição (19) é a restrição de mapeamento dos tempos de viagem para deslocamento entre vértices do grafo, devidamente linearizada. A restrição (20) indica que, para um conjunto de vértices que se encontra sob uma zona de risco, o tempo de trânsito de um veículo por estes vértices deve ser menor do que o tempo máximo tolerado para a exposição ao risco estudado. As restrições (19) e (20) se baseiam em restrições de janela de tempo para roteamento de veículos. Tais restrições têm como objetivo garantir que um serviço seja prestado por um veículo dentro de um intervalo de tempo pré-estabelecido, considerando não apenas o tempo necessário para prestação do serviço, mas também o tempo de deslocamento até o local onde o serviço será realizado. Desta forma, o modelo apresentado, utiliza-se restrições de mapeamento de tempos de viagem de cada veículo para garantir que veículos passem por áreas afetadas não permaneçam dentro destas áreas por um intervalo de tempo maior que o necessário para prestação de seu serviço: evacuar os colaboradores de áreas de risco. A restrição (21) indica a natureza binária das variáveis.

\subsubsection{Modelo para Seleção de Rotas dos Veículos a partir dos Pontos de Reunião}

O segundo modelo (roteamento dos veículos a partir dos PR) possui a mesma função objetivo do primeiro modelo (roteamento dos veículos a partir dos estacionamentos), minimizar o somatório dos tempos necessários para os veículos evacuarem a refinaria, de modo que sua função objetivo é dada pela equação (12). Além disso, as restrições (13) - (14) e (18) - (21) são mantidas. Somam-se a estas as seguintes restrições:

$$
\begin{array}{ll}
\sum_{p \in P R} X_{o p k} \leq 1, & \forall k \in K \\
\sum_{k \in K} X_{o p k}=N O_{p}, & \forall p \in P R
\end{array}
$$


A restrição (22) indica que cada um dos veículos deve partir de um único PR. A restrição (23) indica que o número de veículos que sai de um PR é igual ao número que entra no PR (obtido após a execução da primeira parte do estágio 2).

O segundo modelo permite obter as rotas ótimas para os veículos coletarem os colaboradores nos PR e evacuarem a refinaria. Além disso, permite obter o número mínimo de veículos necessários para evacuação e quais estacionamentos devem realmente ser utilizados.

\section{Experimentação e Aplicação do Modelo}

Os modelos são resolvidos utilizando a ferramenta Xpress IVE 7.7, executado em um sistema Windows 7 (32 bits) com $2 \mathrm{~GB}$ de memória principal e processador dual core AMD Athlon 7750.

O tempo de execução total dos três modelos para obtenção da solução ótima (de todo processo de evacuação) é de aproximadamente 193s. A execução do modelo relativo ao primeiro estágio de evacuação apresenta um total de 1.048 .577 variáveis com 4.755 restrições. O segundo estágio de evacuação apresenta 71.471 variáveis com 72.280 restrições. Estes dados são relativos à execução da experimentação das instâncias descritas nas seções $4.1 \mathrm{e} 4.2$ e foram coletados a partir do relatório de execução da ferramenta Xpress IVE 7.7.

Para demonstrar a aplicabilidade do modelo apresentado, foram utilizados dados de uma refinaria de grande porte para simulação de um vazamento de Sulfeto de Hidrogênio $\left(\mathrm{H}_{2} \mathrm{~S}\right)$ de um dos tanques da refinaria. Para isto, dois cenários do problema são apresentados abaixo. Inicialmente, é considerado um vazamento de $\mathrm{H}_{2} \mathrm{~S}$ durante o turno da manhã, em seguida, um segundo cenário é brevemente discutido, considerando um vazamento da mesma substância no turno da noite. Os dois turnos de trabalho são considerados para analisar o impacto de diferentes condições meteorológicas e da variação climática na dispersão de um vazamento químico e, consequentemente, nas rotas de evacuação da refinaria. É importante observar que para ambos os cenários, o número de pessoas em cada unidade, número de veículos e número de Pontos de Reunião é o mesmo, havendo variação apenas nas condições climáticas, mais especificamente, na direção de incidência do vento no local do acidente.

Para selecionar as rotas de fuga de uma refinaria é necessário identificar suas características, de modo a entender como sua configuração impacta os resultados do modelo proposto.

\subsection{A Refinaria}

Os dados relativos às vias e PR da refinaria representam uma refinaria real. Os demais dados apresentados, como veículos e localização das unidades produtivas são fictícios, por motivos de confidencialidade.

A refinaria em questão possui 3945 colaboradores, distribuídos por 16 unidades produtivas, esta distribuição é apresentada na Tabela 1.

A localização das unidades é mostrada pelos triângulos alaranjados apresentados na Figura 5. Além disso, é possível identificar na Figura 5 as saídas da refinaria, representadas pelos retângulos azuis, os estacionamentos dos veículos, representados por retângulos vermelhos e os PR, representados pelos círculos com seus respectivos identificadores.

Tabela 1: Relação de colaboradores por unidade.

\begin{tabular}{c|c|c|c|c|c|c|c|c}
\hline Un. & \multicolumn{1}{c}{$\boldsymbol{1}$} & $\mathbf{2}$ & $\mathbf{3}$ & $\mathbf{4}$ & $\mathbf{5}$ & $\mathbf{6}$ & $\mathbf{7}$ & $\boldsymbol{8}$ \\
\hline Col. & 282 & 47 & 7 & 19 & 244 & 213 & 52 & 260 \\
\hline Un. & $\mathbf{9}$ & $\mathbf{1 0}$ & $\mathbf{1 1}$ & $\mathbf{1 2}$ & $\mathbf{1 3}$ & $\mathbf{1 4}$ & $\mathbf{1 5}$ & $\mathbf{1 6}$ \\
\hline Col. & 1182 & 117 & 14 & 22 & 193 & 615 & 168 & 510 \\
\hline
\end{tabular}

Fonte: Elaborada pelos autores. 
Além disso, existem 11 PR disponíveis para agrupar os funcionários evacuados. Suas capacidades são mostradas na Tabela 2. A localização dos PR é mostrada na Figura 5.

Tabela 2: Relação de PR e suas respectivas capacidades.

\begin{tabular}{llllllllllll}
\hline $\boldsymbol{P R}$ & $\mathbf{1}$ & $\mathbf{2}$ & $\mathbf{3}$ & $\mathbf{4}$ & $\mathbf{5}$ & $\mathbf{6}$ & $\mathbf{7}$ & $\mathbf{8}$ & $\mathbf{9}$ & $\mathbf{1 0}$ & $\mathbf{1 1}$ \\
\hline Capac. & 800 & 700 & 1100 & 1400 & 750 & 400 & 500 & 1050 & 1200 & 800 & 600 \\
\hline \multicolumn{1}{c}{ Fonte: Elaborada pelos autores. }
\end{tabular}

A frota de veículos disponível para evacuação da refinaria é composta por 70 veículos, cada um com capacidade de transporte de 90 pessoas. Os veículos são distribuídos por 3 estacionamentos na refinaria, com capacidade para 30, 20 e 20 veículos, respectivamente. A localização dos estacionamentos é mostrada na Figura 5.

As vias da refinaria podem ser observadas na Figura 5. A capacidade de trânsito para cada via é de seis veículos. As vias ressaltadas na cor laranja, observadas na Figura 5, possuem velocidade máxima de trânsito de $54 \mathrm{~km} / \mathrm{h}$, as demais vias possuem velocidade máxima de trânsito de $30 \mathrm{~km} / \mathrm{h}$.

Figura 5: Localização de estacionamentos, unidades, PR e saídas da refinaria.

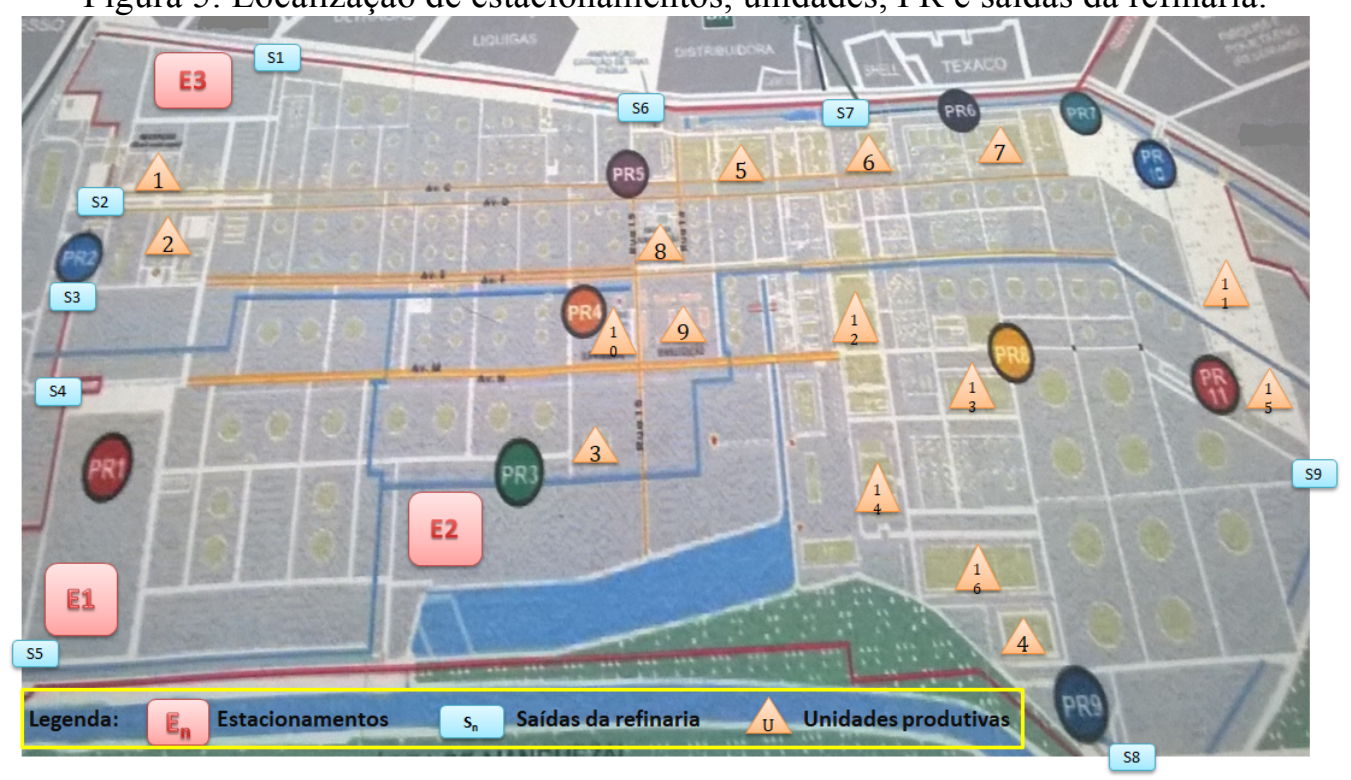

Fonte: Elaborada pelos autores.

\subsection{Definição do Acidente}

$\mathrm{O}$ acidente simulado neste estudo é o vazamento de $\mathrm{H}_{2} \mathrm{~S}$ de um dos tanques de armazenamento, na área de estocagem da refinaria. $\mathrm{O}_{2} \mathrm{~S}$ é um gás incolor, inflamável e altamente tóxico, conhecido pelo seu odor de "ovo podre" em baixas concentrações.

A principal forma de exposição ao gás é através da inalação, uma vez que o gás é rapidamente absorvido pelos pulmões. Os efeitos à saúde causados pela exposição ao $\mathrm{H}_{2} \mathrm{~S}$ dependem da concentração inalada pelo indivíduo e do tempo de exposição ao gás e variam desde efeitos leves, como dores de cabeça e irritação nos olhos a problemas graves de saúde como edemas pulmonares e inconsciência e podem levar à morte (OSHA, 2016).

Para simulação do vazamento no ALOHA são utilizados os seguintes dados:

- O vento local viaja da direção Sul-Sudeste (SSE) a uma velocidade de $11,2 \mathrm{~km} / \mathrm{h}$, direção e velocidade predominantes na região da refinaria (durante o dia), e sua velocidade é medida a uma altura de $3 \mathrm{~m}$ acima do solo. Para o segundo cenário (vazamento durante o turno da noite), considera-se que o vento viaja a $11,2 \mathrm{~km} / \mathrm{h}$ na direção Norte-Noroeste (NNW), vento predominante no período da noite. 
- O terreno ao redor dos tanques de armazenagem é gramado e existem poucos edifícios ao redor, de modo que o local é considerado "campo aberto" e não há necessidade de especificação direta das propriedades do solo nas configurações do software.

- O céu está claro e com poucas nuvens, a temperatura do ar no local é de $23^{\circ} \mathrm{C}$. A umidade relativa do ar está em $50 \%$.

- $\mathrm{O} \mathrm{H}_{2} \mathrm{~S}$ é armazenado em um tanque cilíndrico, vertical, de 500 galões de capacidade. Possui 1,21 m de diâmetro e 1,62 m de altura. A substância é armazenada na forma líquida e a temperatura ambiente.

- No momento do acidente, o tanque está com sua capacidade total, 500 galões. A massa do tanque cheio é $1,65 \mathrm{t}$.

- A substância está vazando do tanque através de um furo e não está queimando.

- O tanque possui uma fissura circular, responsável pelo vazamento, de $15,24 \mathrm{~cm}$ de diâmetro, que se encontra a $25,4 \mathrm{~cm}$ de altura em relação ao fundo do tanque.

O resultado deste vazamento é uma nuvem de vapor tóxica estacionária, conforme calculado pelo ALOHA e mostrado nas Figuras 6a (vazamento durante o dia) e 6b (vazamento durante a noite).

As Figuras 5, 6a e 6b, juntamente com as informações apresentadas na Tabela 3, permitem identificar o tempo limite de exposição para cada área de risco apresentada. Este estudo considera apenas a zona de risco vermelha, que apresenta uma concentração de $100 \mathrm{ppm}$ de H2S, uma vez que os riscos à saúde das zonas de risco amarela e laranja são muito pequenos e se estendem muito além dos limites da refinaria. A tolerância à exposição de 100 ppm sem danos à saúde é de 2 minutos, como mostrado na Tabela 3, por isso neste estudo o tempo máximo de exposição tolerado $(\delta)$ é considerado como 1,5 minutos (90 segundos).

Figura 6: Áreas afetadas pelo vazamento.

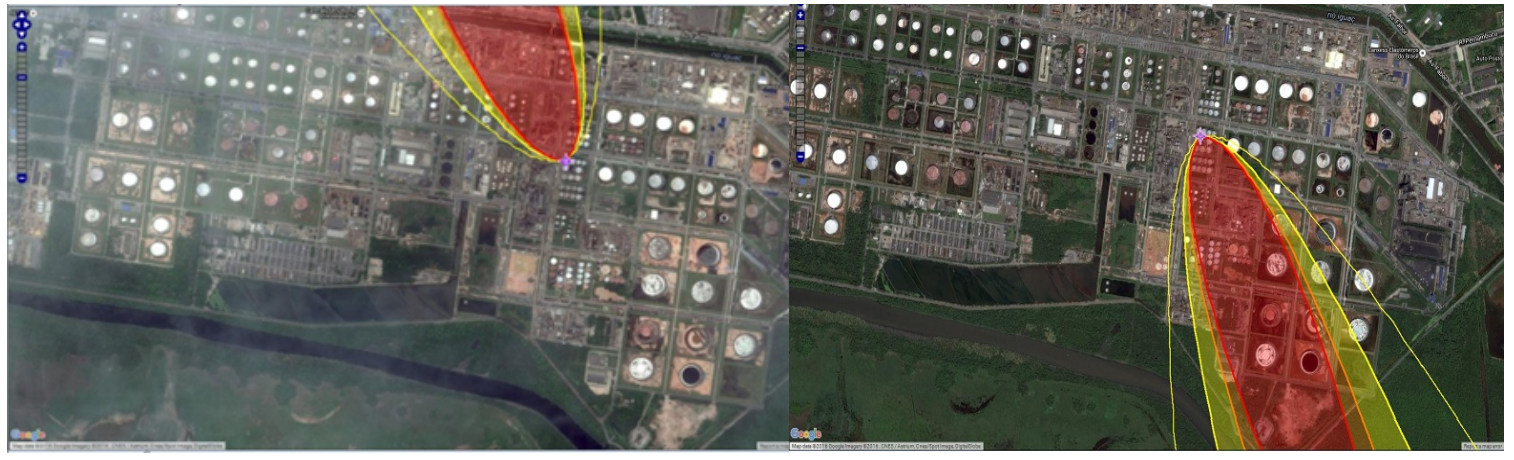

a) turno da manhã

b) turno da noite

Fonte: Elaborada pelos autores.

\section{Resultados}

\subsection{Resultado do Primeiro Cenário - Turno da Manhã}

A aplicação do modelo relativo ao primeiro estágio da evacuação permite identificar as rotas ótimas para a evacuação dos trabalhadores de cada uma das 16 unidades produtivas em direção a um dos PR, a distância percorrida pelos colaboradores de cada unidade, os PR a serem utilizados por cada colaborador e o número de pessoas atribuídas a cada um dos PR durante a evacuação.

A distância máxima percorrida $(R)$ por um colaborador partindo de sua unidade em direção a um dos PR é de 681 metros, percorridos pelos colaboradores da unidade 12 para que se dirijam ao PR 8. Esta rota é destacada em verde na Figura 7. As vias apresentadas em vermelho na Figura 7 representam as vias afetadas pelo vazamento e por isso não podem ser utilizadas para evacuação. 
Tabela 3: Efeitos da exposição ao $\mathrm{H}_{2} \mathrm{~S}$ ao ser humano.

\begin{tabular}{|c|c|}
\hline $\begin{array}{l}\text { Concentração } \\
\text { (ppm) }\end{array}$ & Sintomas/efeitos \\
\hline $0.00011-0.00033$ & Níveis normais no ar \\
\hline $0.01-1.5$ & Percepção de odor de "ovo podre". \\
\hline $2-5$ & $\begin{array}{l}\text { Exposição prolongada pode causar náusea, lacrimação dos olhos, dores de } \\
\text { cabeça, perda de sono e problemas respiratórios para pacientes com asma. }\end{array}$ \\
\hline $5-20$ & $\begin{array}{l}\text { Fadiga, perda de apetite, dores de cabeça, irritabilidade, perda de memória } \\
\text { e tontura. }\end{array}$ \\
\hline $20-100$ & Conjuntivite e irritação no trato respiratório \\
\hline 100 & $\begin{array}{l}\text { Após } 2 \text { minutos: Tosse, irritação nos olhos, perda do olfato. } \\
\text { Após } 15 \text { minutos: Dificuldades para respirar, tontura, irritação na garganta. } \\
\text { Aumento gradual da gravidade dos sintomas após algumas horas. } \\
\text { Após } 48 \text { horas: morte. }\end{array}$ \\
\hline $100-150$ & Perda de olfato (paralisia olfativa). \\
\hline $150-300$ & $\begin{array}{l}\text { Conjuntivite e irritação do trato pulmonar. Edemas pulmonares podem } \\
\text { surgir após } 1 \text { hora de exposição. }\end{array}$ \\
\hline $300-700$ & $\begin{array}{l}\text { Até } 5 \text { minutos: Gagueira e inconsciência. } \\
\text { Até } 30 \text { minutos: Sérios danos aos olhos. } \\
\text { Após } 30 \text { minutos: Morte }\end{array}$ \\
\hline $700-1000$ & $\begin{array}{l}\text { Rápida perda de consciência. Respiração é interrompida após } 1 \text { ou } 2 \\
\text { inspirações do gás. Morte em minutos }\end{array}$ \\
\hline $1000-2000$ & Morte praticamente instantânea. \\
\hline
\end{tabular}

Fonte: adaptado de https://www.osha.gov/SLTC/hydrogensulfide/hazards.html, acesso em $04 / 02 / 2016$.

Figura 7: Rota ótima para evacuação dos colaboradores da unidade 12.

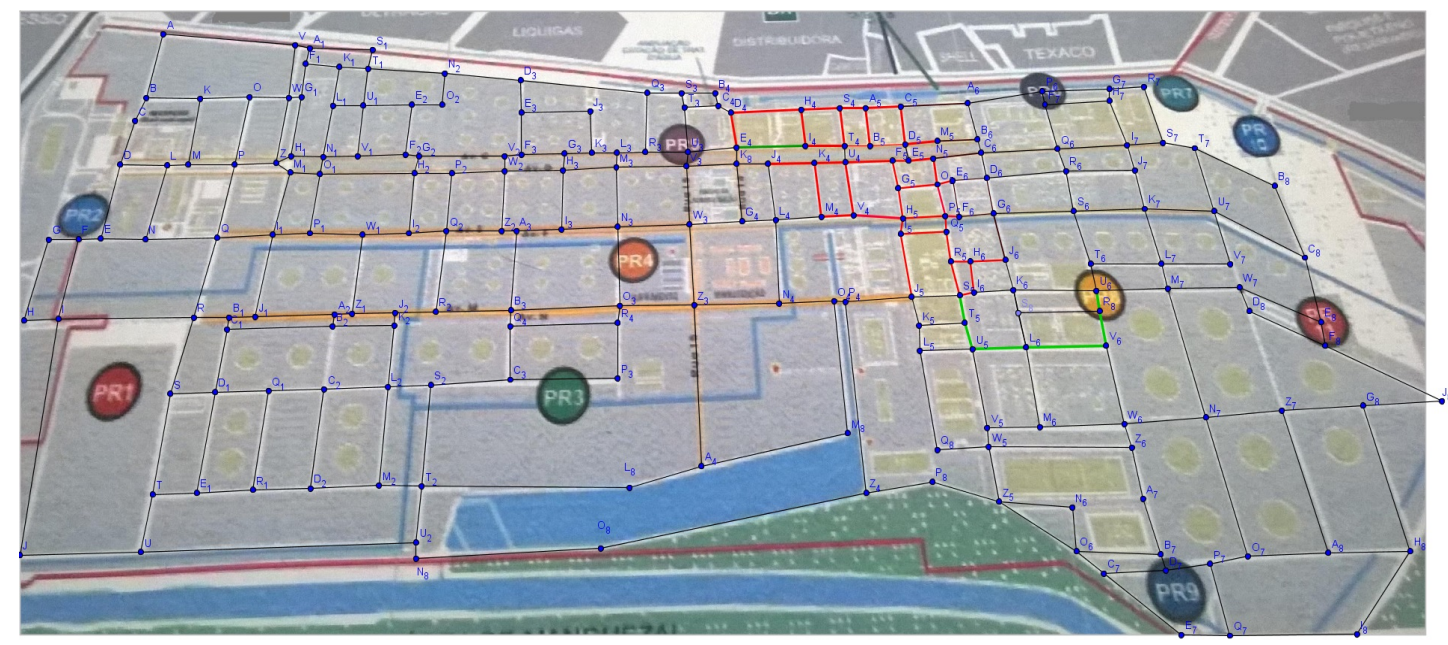

Fonte: Elaborada pelos autores. 
A execução do modelo permite identificar para quais PR os funcionários de cada unidade devem se dirigir e, consequentemente, o número de pessoas alocadas em cada um dos PR, como mostrado na Tabela 4.

Tabela 4: Funcionários de unidades alocados em cada um dos PR.

\begin{tabular}{|c|c|c|c|c|c|c|c|c|c|c|c|}
\hline PR & 1 & 2 & 3 & 4 & 5 & 6 & 7 & 8 & 9 & 10 & 11 \\
\hline $\begin{array}{c}\text { Funcionários } \\
\text { alocados }\end{array}$ & Un1 & Un2 & Un3 & $\begin{array}{l}\text { Un9, } \\
\text { Un10 }\end{array}$ & $\begin{array}{l}\text { Un5, } \\
\text { Un8 }\end{array}$ & $\begin{array}{l}\text { Un6, } \\
\text { Un7 }\end{array}$ & -- & Un12 & $\begin{array}{l}\text { Un4, } \\
\text { Un14, } \\
\text { Un16 }\end{array}$ & -- & $\begin{array}{l}\text { Un11, } \\
\text { Un13, } \\
\text { Un15 }\end{array}$ \\
\hline $\mathrm{N}^{\circ}$ pessoas & 282 & 47 & 7 & 1299 & 504 & 265 & 0 & 22 & 1144 & 0 & 375 \\
\hline
\end{tabular}

Fonte: Elaborada pelos autores.

De posse destes dados os veículos podem começar a evacuação dos $P R$, durante o $2^{\circ}$ estágio da evacuação. Os modelos do segundo estágio identificam que o maior tempo necessário para um veículo partir de um estacionamento e chegar a um dos PR é de 359,25 s, tempo necessário para que o veículo 2 chegue ao PR 9, partindo do estacionamento 3. A rota ótima do veículo 2 é destacada em verde na Figura 8. A soma dos tempos para que todos os veículos cheguem aos PR aos quais estão designados (Função Objetivo) é 7617,27 s.

A Figura 8 permite observar que o veículo 2 trafega por uma das zonas de risco, porém o tempo necessário para atravessá-la é menor do que o tempo de exposição máximo permitido.

Figura 8: Rota para que o veículo 2 chegue ao PR 9 para extração dos evacuados.

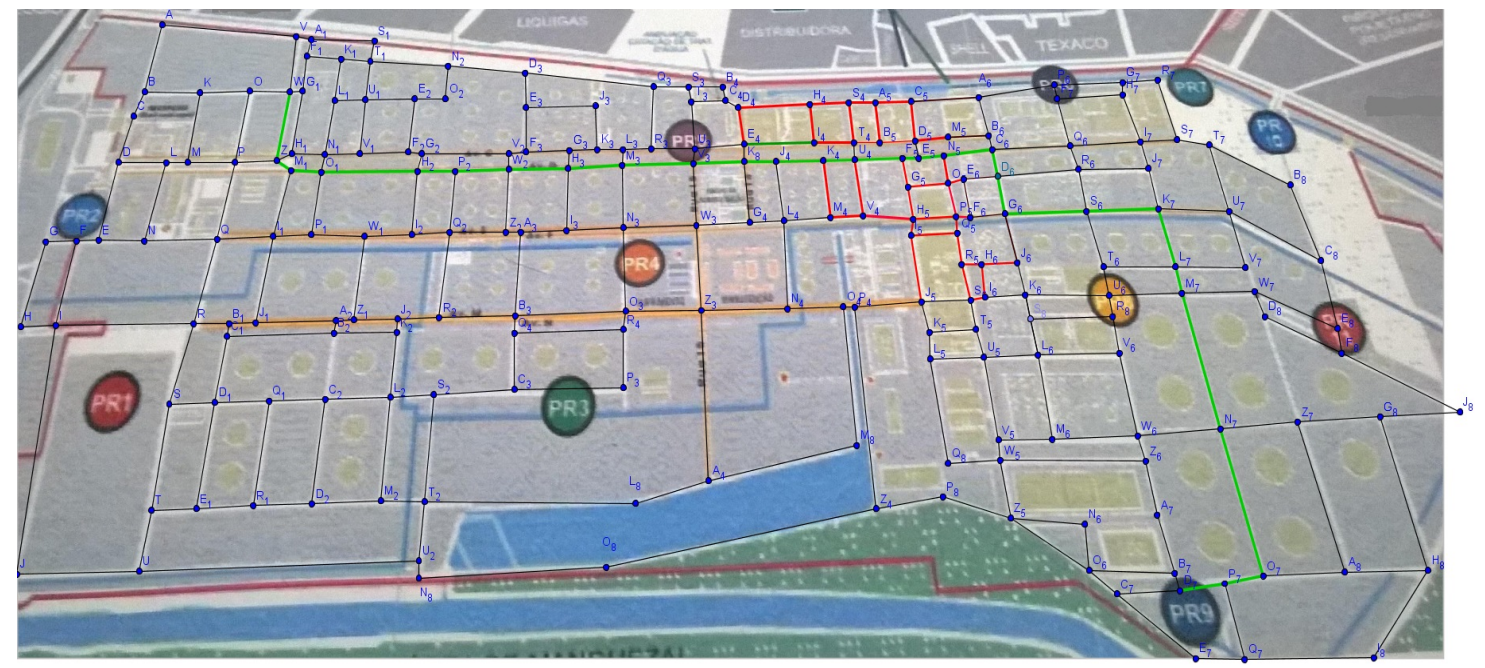

Fonte: Elaborada pelos autores.

Além disso, os modelos permitem identificar a quantidade de veículos necessários para evacuar cada um dos PR, como é apresentado na Tabela 5.

Tabela 5: Número de veículos necessários para evacuação de cada um dos PR.

\begin{tabular}{cccccccccccc}
\hline PR & $\mathbf{1}$ & $\mathbf{2}$ & $\mathbf{3}$ & $\mathbf{4}$ & $\mathbf{5}$ & $\mathbf{6}$ & $\mathbf{7}$ & $\mathbf{8}$ & $\mathbf{9}$ & $\mathbf{1 0}$ & $\mathbf{1 1}$ \\
\hline $\mathrm{N}^{\circ}$ Veículos & 4 & 1 & 1 & 15 & 6 & 3 & 0 & 1 & 13 & 0 & 5 \\
\hline
\end{tabular}

Fonte: Elaborada pelos autores.

Também é possível identificar que partem 9, 20 e 20 veículos dos estacionamentos 1,2 e 3 , respectivamente, totalizando 49 veículos. Identificando, assim, o número de veículos necessários em cada estacionamento, durante o dia, para a realização do plano de evacuação. 
Além disso, o modelo permite observar que o maior tempo necessário para que um veículo parta de um estacionamento e evacue a refinaria, passando por um dos PR, é de 359,25 s (desconsiderando tempo de embarque dos evacuados no veículo), necessários para que o veículo 2 parta do estacionamento 3, evacue o PR 9 e se dirija a saída 8 adjacente ao PR. Uma vez que a saída é adjacente ao PR9 o tempo de trânsito entre o PR e a saída é virtualmente nulo, sendo desconsiderado, o que torna a rota do veículo igual a apresentada na Figura 8. A soma dos tempos necessários para evacuação de todos os veículos, partindo de um dos PR em direção as saídas da refinaria, é de 1650,92 s.

\subsection{Resultado do Segundo Cenário - Turno da Noite}

A observação das Figuras 5 e 6 b permite constatar que o PR 9 fica sob uma das áreas afetadas pelo vazamento no turno da noite, portanto não deve ser utilizado para evacuação dos colaboradores. Desta forma, os funcionários que são alocados ao PR 9 durante a evacuação no turno da manhã precisam ser alocados em outros PR. A Tabela 6 a seguir apresenta a quais PR os colaboradores de cada unidade são alocados durante o turno da noite, e o número de colaboradores em cada um dos PR.

Tabela 6: Funcionários de unidades alocados por PR no turno da noite.

\begin{tabular}{ccccccccccccccc}
\hline PR & 1 & 2 & 3 & 4 & 5 & 6 & 7 & 8 & 9 & 10 & 11 \\
\hline $\begin{array}{c}\text { Funcionários } \\
\text { alocados }\end{array}$ & Un2 & Un1 & Un16 & $\begin{array}{c}\text { Un3, } \\
\text { Un9, }\end{array}$ & $\begin{array}{c}\text { Un5, } \\
\text { Un10 }\end{array}$ & Un8 & Un6 & -- & $\begin{array}{c}\text { Un4,Un7, } \\
\text { Un12,Un } \\
13, \\
\text { Un14 }\end{array}$ & -- & Un11 & $\begin{array}{c}\text { Un1 } \\
5\end{array}$ \\
\hline $\begin{array}{c}\mathrm{N}^{\circ} \text { de } \\
\text { pessoas }\end{array}$ & 47 & 282 & 510 & 1306 & 504 & 213 & 0 & 901 & 0 & 14 & 168 \\
\hline
\end{tabular}

Fonte: Elaborada pelos autores.

O PR9 é um dos PR mais utilizados para evacuação durante o dia, recebendo 1144 colaboradores durante o processo de evacuação. Porém, situa-se em uma região de risco caso o vazamento aconteça à noite, o que faz com que 1144 colaboradores precisem percorrer maiores distâncias para evacuar suas unidades de produção, impactando diretamente o tempo necessário para evacuação dos colaboradores, uma vez que os funcionários das unidades 4,14 e 16, que eram anteriormente direcionados ao PR 9, precisam percorrer $1651 \mathrm{~m}, 1145 \mathrm{~m}$ e $1595 \mathrm{~m}$, respectivamente, para atingir seus novos PR. Isto demonstra a necessidade da criação de um novo PR para receber os colaboradores destas unidade caso um acidente aconteça no turno da noite, uma vez que os PR mais próximos, além do PR9, situam-se a mais de $1 \mathrm{~km}$ das respectivas unidades.

A maior distância percorrida $(\mathrm{R})$ por um colaborador é de $1651 \mathrm{~m}$, necessários para os colaboradores da unidade 4 chegarem até o PR 8, contornando as zonas de risco. Um aumento significativo na distância máxima quando comparado ao cenário anterior, que é de $681 \mathrm{~m}$.

$\mathrm{O}$ número de veículos necessários para evacuação se mantém o mesmo, 49 veículos. $\mathrm{O}$ tempo total necessário para que os veículos evacuem os PR sofre um leve acréscimo, passando de 9310 s no primeiro cenário para 9380 s no segundo cenário. De modo que a substituição dos PR utilizados não afeta de forma considerável o tempo necessário para evacuação dos veículos. Isto acontece devido à necessidade de todos os veículos evacuarem a refinaria após buscar os colaboradores nos PR. De fato, embora a mudança na alocação dos colaboradores aos PR acarrete uma diminuição no tempo total necessário para os veículos chegarem aos PR (de $7570 \mathrm{~s}$ para $6022 \mathrm{~s}$ ), eles ficam proporcionalmente mais distantes das saídas da refinaria, aumentando o tempo de viagem dos PR até as saídas de 1740s para 3360s.

O maior tempo necessário para um veículo partir de um estacionamento e chegar a um dos PR é de 292,5 segundos, necessários para o veículo 8 partir do estacionamento 1 e se dirigir ao PR 8. O maior tempo necessário para um veículo partir de um PR e chegar a uma das saídas é de 138,15 s, tempo necessário para o veículo 6 partir do PR3 e se dirigir a saída 7 . 
Por fim, a Tabela 7 apresenta o número de veículos necessários para evacuar cada um dos PR.

Tabela 7: Número de veículos necessários para evacuar os PR no turno da noite.

\begin{tabular}{cccccccccccc}
\hline PR & $\mathbf{1}$ & $\mathbf{2}$ & $\mathbf{3}$ & $\mathbf{4}$ & $\mathbf{5}$ & $\mathbf{6}$ & $\mathbf{7}$ & $\mathbf{8}$ & $\mathbf{9}$ & $\mathbf{1 0}$ & $\mathbf{1 1}$ \\
\hline $\mathrm{N}^{\mathrm{o}}$ Veículos & 1 & 4 & 6 & 15 & 6 & 3 & 0 & 11 & 0 & 1 & 2 \\
\hline
\end{tabular}

Fonte: Elaborada pelos autores.

\section{Considerações Finais}

Modelos de roteamento de pessoas e veículos para evacuação em dois estágios de uma refinaria, utilizando ferramentas de análise e modelagem de risco e Sistemas de Informações Geográficas (SIG), foram propostos para seleção de rotas de fuga para evacuação de uma refinaria de petróleo, onde o objetivo é minimizar a distância percorrida e tempo necessário para evacuação de pessoas e veículos da planta industrial.

Observa-se que o modelo proposto é capaz não apenas de encontrar as rotas ótimas (menores e mais seguras) a serem percorridas para cada estágio da evacuação, mas também é capaz de identificar, através da análise da utilização dos arcos do grafo, quais os PR, estacionamentos e saídas da refinaria devem ser utilizados para cada tipo de acidente, e a quantidade de pessoas/veículos que utiliza cada uma destas facilidades, podendo ser considerado um modelo de localização-roteamento de veículos e pessoas. Neste ponto, é importante observar que as rotas ótimas são pontos ótimos locais, resultado da decomposição por estágio, normalmente adotada, dos planos de evacuação de área.

Através da utilização do GIS MARPLOT é possível determinar, de forma precisa, a extensão da área afetada pelo vazamento e o tempo máximo de exposição permitido aos colaboradores dentro desta área, permitindo identificar as áreas de risco na indústria e as vias da refinaria que devem ser evitadas durante a evacuação da área, aumentando a segurança para trabalhadores e equipes de resgate durante a evacuação.

Aliada ao MARPLOT, a ferramenta ALOHA permite mapeamento e análise de vazamentos de mais de 1000 produtos químicos distintos, permitindo a aplicação do modelo apresentado neste trabalho em plantas industriais petroquímicas (não apenas refinarias de petróleo) de diferentes tipos e em diferentes condições geográficas e climáticas. De modo que o estudo demonstra a aplicabilidade de Sistemas de Modelagem de Riscos e SIG para preparação e resposta a diferentes situações de emergência em diferentes instalações industriais.

Os modelos propostos podem ser considerados eficientes, pois se baseiam na modelagem clássica de fluxo em grafos direcionados, permitindo sua aplicação em problemas de maior escala com relativa facilidade de implementação. Porém, nota-se que para solução de problemas em grande escala é necessária utilização de máquinas (computadores) com alto desempenho, uma vez que para grafos com um grande número de vértices, como a representação de mapas de grandes áreas, o modelo exige grande quantidade de memória física.

Este trabalho ainda permite identificar a necessidade da criação de novos pontos de reunião próximos às unidades de produção 4,14 e 16 da refinaria em estudo, que abrigam grande quantidade de colaboradores, uma vez que existe apenas um PR próximo a estas unidades (PR9). Em um eventual acidente que comprometa a integridade deste PR (como no caso simulado no segundo cenário deste estudo), os colaboradores precisam percorrer grandes distâncias a pé, dentro de um ambiente industrial, para chegar a um dos PR disponíveis. Isto compromete não apenas uma execução eficiente do plano de evacuação, mas, principalmente, põe em risco a saúde e segurança dos colaboradores destas unidades.

Desta forma, a implantação do modelo em diferentes cenários fornece às empresas petroquímicas a oportunidade de estudar a localização de seus PR e identificar oportunidades de melhoria em suas instalações.

Recomenda-se como estudo futuro a generalização do modelo proposto neste trabalho para que possa ser utilizado para evacuação em regiões urbanas, considerando suas 
características e particularidades, em situações em que vazamentos químicos atinjam uma área superior aos limites da planta industrial, como ocorrido em Bophal (1984) e no Porto de Santos (2016).

Por fim, uma nova pesquisa está sendo desenvolvida atualmente comparando o resultado do modelo proposto com outros modelos de evacuação de área, incluindo um modelo único desenvolvido para o mesmo problema.

Agradecimentos. Os autores gostariam de agradecer a ANP/Petrobras pelo incentivo recebido através do programa PRH21, sem o qual esta pesquisa não poderia ter sido desenvolvida.

\section{Referências}

Alçada-Almeida, L., Tralhão, L., Santos, L. e Coutinho-Rodriguez, J. A multiobjective approach to locate emergency shelters and identify evacuation routes in urban areas. Geographical Analysis, v. 41, n. 1, p. 9-29, 2009.

Brachman, M. L. e Dragicevic, S. A spatially explicit network science model for emergency evacuations in an urban context. Computers, Environment and Urban Systems, v. 44, p. 15-26, 2014.

Campos, V., Bandeira, R. e Bandeira, A. A method for evacuation route planning in disaster situations. Procedia - Social and Behavioral Sciences, v. 54, p. 503-512, 2012.

Cova, T. J. e Church, R. L. Modelling community evacuation vulnerability using GIS. International Journal of Geographical Information Science, v. 11, n. 8, p. 763-784, 1997.

Cova, T. J. e Johnson, J. P. A network flow model for lane-based evacuation routing. Transportation Research Part A: Policy and Practice, v. 37, n. 7, p. 579-604, 2003.

ILO - International Labour Organisation. Major hazard Control - A practical manual. Genebra, Suíça: International Labour Office, 1988. 296 p.

Johnson Jr, J. H. e Zeigler, D. J. Evacuation planning for technological hazards: An emerging imperative. Cities,v. 3, n. 2, p. 148-156, 1986.

Kalafatas, G. e Peeta, S. Planning for evacuation: Insights from an efficient network design model. Journal of Infrastructure Systems, v. 15, n. 1, p. 21-30, 2009.

Liu, Y., Lai, X. e Chang, G.-L. Two-level integrated optimization system for planning of emergency evacuation. Journal of Transportation Engineering, v. 132, n. 10, p. 800-807, 2006.

Marinho, F., Munari, P., Moreno, A. e Alem, D. Uma ferramenta baseada em otimização para apoiar decisões de preparação e resposta em logística humanitária. Pesquisa Operacional para o Desenvolvimento, v. 10, n.2, p. 70-92, 2018.

OSHA - Occupational Safety and Health Association. Hydrogine Sulfide hazards. 2016. Disponível em: https:/www.osha.gov/SLTC/hydrogensulfide/hazards.html. Acesso em: 08/03/2016.

Pidd, M., De Silva, F. N. e Eglese, R. W. A simulation model for emergency evacuation. European Journal of Operational Research, v. 90, n. 3, p. 413-419, 1996. 
Saadatseresht, M., Mansourian, A. e Taleai, M. Evacuation planning using multiobjective evolutionary optimization approach. European Journal of Operational Research, v. 198, n. 1, p. 305-314, 2009.

Yamada, T. A network flow approach to a city emergency evacuation planning. International Journal of Systems Science, v. 27, n. 10, p. 931-936, 1996.

Yi, W. e Özdamar, L. A dynamic logistics coordination model for evacuation and support in disaster response activities. European Journal of Operational Research, v. 179, n. 3, p. 1177$1193,2007$. 